\title{
New Technology for Developing a Lightweight Refiner Plate for Hardwood Kraft Pulp Fibers
}

\author{
Byeong-Geol Min, ${ }^{\mathrm{a}}$ Ji-Young Lee, ${ }^{\mathrm{b}}$ Chul-Hwan Kim,,${ }^{\mathrm{b}} *$ See-Han Park, ${ }^{\mathrm{c}}$ Min-Seok Lee, ${ }^{\mathrm{d}}$ \\ Ho-Gyeong Gu, ${ }^{d}$ and Chang-Young Lee ${ }^{d}$
}

\begin{abstract}
Sand casting makes it difficult to manufacture a fine bar plate for low intensity refining. This study introduced a novel technology for manufacturing lightweight fine bar plates and compared the effects to traditional bar plates. The lightweight fine bar plate base was manufactured using a lightweight aluminum alloy and stainless-steel. Because the bars were inserted into the plate vertically without the draft angle, the stock throughput was improved by approximately $27 \%$ compared to the sand-casted bar plates. Additionally, the lightweight fine bar plate maximized internal and external fibrillation while minimizing fiber length loss. In conclusion, the lightweight fine bar plate was shown to be more effective in improving the strength properties of paper and reducing energy consumption.
\end{abstract}

Keywords: Hardwood pulp; Cutting edge length; Lightweight fine bar; Refining; Draft angle

Contact information: a: Representative director, KOS1 Inc., Gimhae, Korea; b: Professor, Department of Environmental Material Science, IALS, Gyeonsang National University, Jinju, Korea 52828, c: Advisory Professor, Major of Pulp \& Paper Chemical Engineering, Gyeongsang National University, Jinju, Korea 52828; d: Graduate students, Dept. of Forest Products, Gyeongsang National University, Jinju, Korea 52828; *Corresponding author: jameskim@gnu.ac.kr

\section{INTRODUCTION}

The refining process is considered to be the heart of the papermaking process because it affects the paper machines' runnability and paper properties. Most companies that manufacture refiner plates are greatly interested in producing fine or ultra-fine bar plates. Refiner plates with fine bar patterns enable low intensity or ultra-low intensity refining. Nissan (1977) suggested that the theoretical maximum intensity limit for modifying hardwood fibers was $5.4 \mathrm{~kJ} / \mathrm{kg} \cdot$ impact (Nissan 1977). When this was applied to Kerekes' model (Kerekes 1990), the refining intensity was equal to $0.1 \mathrm{Ws} / \mathrm{m}$. Baker (1995) recommended that the typical SEL (specific edge load) values for chemical pulp should be $2 \mathrm{~J} / \mathrm{m}$ for softwood and $0.2 \mathrm{~J} / \mathrm{m}$ for hardwood (Baker 1995). The typical intensity range for hardwood pulps has been generally established to be 0.2 to $0.6 \mathrm{Ws} / \mathrm{m}$ (Lumiainen 2000). This means that hardwood pulp fibers with short fiber length and thin fiber walls should be treated with many impacts of small intensity for fibrillation (Kerekes 1990; Ratnieks et al. 2007; Robinson et al. 2010). If refining is not well optimized for hardwood pulps, several negative effects will occur, including greater energy consumption, poor development of core paper properties, severe fiber cutting, and fines generation. Therefore, low or ultralow intensity refining for hardwood pulp is desirable to achieve greater bulk and opacity at a given sheet strength.

Before fine bar plates were developed, the lowest specific edge loads (SEL) targeted were 0.6 to $0.8 \mathrm{Ws} / \mathrm{m}$, due to limitations of the manufacturing technology. However, as new technologies for fine bar production began to be introduced, low intensity 
refining of 0.1 to $0.5 \mathrm{Ws} / \mathrm{m}$ started to become available without affecting the hydraulic capacity.

The most used technology for manufacturing refiner plates is the original sand casting technology. This technology must give a draft angle of 3 to $5^{\circ}$ to protect the patterns in the manufacturing process, thereby limiting the hydraulic capacity on low intensity pattern designs (J\&L Fiber Services 2006; Lee et al. 2019). A lost-wax casting technology could be used to manufacture bar plates with no draft angle (Lee et al. 2019). However, it is not easy to reduce the plate weight because there are limitations to the selection of the metal alloy to be used (J\&L Fiber Services 2006). Aikawa developed fine bar plates by fabricating and brazing the bars to the plate base to remove the draft angle from the bar shape. This manufacturing process contributed to the creation of refiner plates with narrow bars and deep grooves, but there were limitations in the selection of alloy materials, changes in pattern design, and weight reduction of plates. Another problem with Aikawa products came from the heavy weight of each bar segment. Aikawa Fiber Technology (AFT) confirmed that reducing the active refining diameter greatly helped to save energy because the no-load power increased exponentially with the diameter of the plate (Ratnieks et al. 2007; Robinson et al. 2010; Müller 2016; AFT catalog 2017). The reduction in the diameter of the plate is also related to the reduction in the plate weight. That is, it can serve as an empirical example to show that when the weight of the plate is reduced, it is effective to reduce the initial rotation energy required for rotating the plate. Andritz developed a Durabond manufacturing technology that precisely cuts stainless steel bars with a laser, inserts them into a laser-cut slot formed on a base plate, and then joins them with a proprietary bonding agent. Andritz introduced a multi-segment design concept for the larger size plate over 26" (Müller 2016). Because several Durabond light segments are mounted and fixed to the base plate over the specified diameter, many screw holes are formed on the segments, which can reduce the refining efficiency. In addition, the segment itself is light, but the total weight of the multi-segments fixed to the base plate is still heavy, and the segments' compatibility with the base plate must be considered when replacing the segments.

In this study, a technique for manufacturing a lightweight fine-bar plate optimized for hardwood pulp fibers was developed by applying a novel method of joining dissimilar metals. The refining effect of this lightweight fine bar plate was compared to that of a default plate that had been prepared by sand casting. Through promoting the superiority of the lightweight refiner vertical bar plate identified through this study to the paper industry, it was intended to contribute to the reduction of refining energy cost and improvement of product quality.

\section{EXPERIMENTAL}

\section{Raw Materials}

Hardwood bleached kraft pulp (HwBKP) was supplied from the Moorim Paper Inc. mill in Jinju, Korea. The dimensional characteristics of HwBKP are summarized in Table 1. The HwBKP was torn into small pieces and soaked in distilled water for $4 \mathrm{~h}$ before disintegration. 
Table 1. Fiber Dimension of HwBKP Used for Refining

\begin{tabular}{|c|c|c|c|c|}
\hline & $\begin{array}{c}\text { Arithmetic Mean Fiber } \\
\text { Length }(\mathrm{mm})\end{array}$ & $\begin{array}{c}\text { Length-weighted Mean } \\
\text { Fiber Length }(\mathrm{mm})\end{array}$ & $\begin{array}{c}\text { Fiber } \\
\text { Width } \\
(\mu \mathrm{m})\end{array}$ & $\begin{array}{c}\text { Coarseness } \\
(\mathrm{mg} / \mathrm{m})\end{array}$ \\
\hline HwBKP & 0.49 & 0.83 & 20.6 & 0.5 \\
\hline
\end{tabular}

\section{Manufacturing Process of the Lightweight Fine-bar Plate}

Conventional refiner plates have been manufactured by sand casting, which has required a draft angle of 2 to $5^{\circ}$ to successfully remove the sand mold for the pattern design prior to closing and pouring (Fig. 1). The sharp corners of the patterns have led to local structural weaknesses such as shrinkage, cracks, tears, and draws (Kay 2002). Refiner plates with the draft angle are considered to minimize the open area of the stock flow zone between bars, stock throughput, and plate life (J\&L Fiber Services 2006; AFT catalog 2017; Lee et al. 2019).
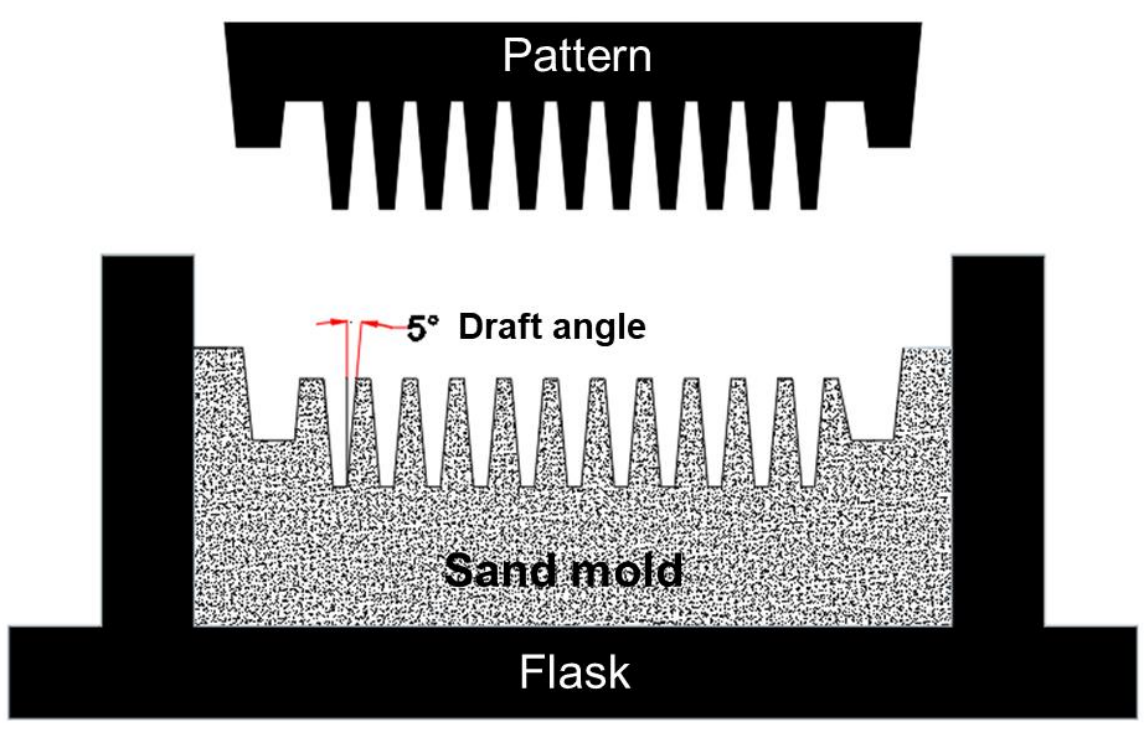

Fig. 1. Draft angle of the sand casting for HwBKP

In contrast, refiner plates with zero-degree draft angles can maximize the area of the stock flow path, plate life, hydraulic capacity, and bar edge sharpness (Ratnieks 2007; Robinson et al. 2010). Nevertheless, it is hardly possible to manufacture refiner plates with a zero-draft angle using existing sand-casting technology.
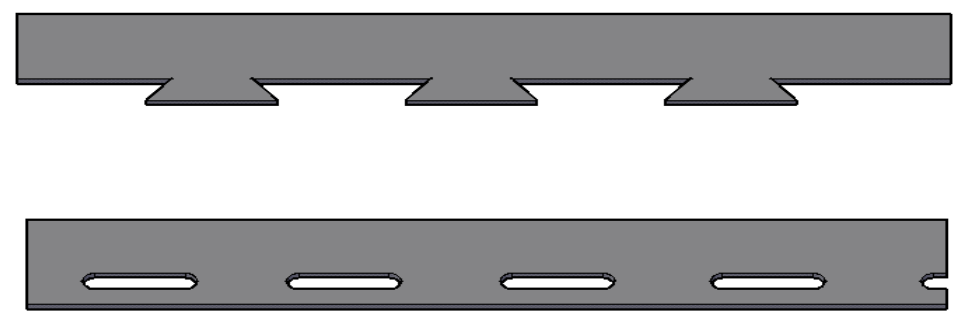

Fig. 2. Bar shapes inserted into plate bases 
To develop bar plates without the draft angle, a new method of inserting bars with holes or wedges cut into a plate base was applied (Fig. 2). To reduce the weight of the plate base, aluminum alloy was used as the main material. As a result, it was expected that the overall weight of the plate could be reduced by about $1 / 2$ compared to the sand-casting plate.

The bars were pre-cut with a laser to the desired dimensions. Heat treatment was performed at approximately $1,100{ }^{\circ} \mathrm{C}$ to improve the strength of the pre-cut bars. If the stainless-steel bars were not heat-treated, the hardness would decrease during the casting process, causing deformation of the bars during plate use. Hardness of the stainless-steel bars was measured under a load of $150 \mathrm{~kg}$ and a loading time of $30 \mathrm{~s}$ using the Rockwell hardness tester (DTR-300; Daekyung TECH, Incheon, Korea).

The first step to make a lightweight fine bar plate was to insert the bars into an assembly jig (refer to Step 1 in Fig. 3).

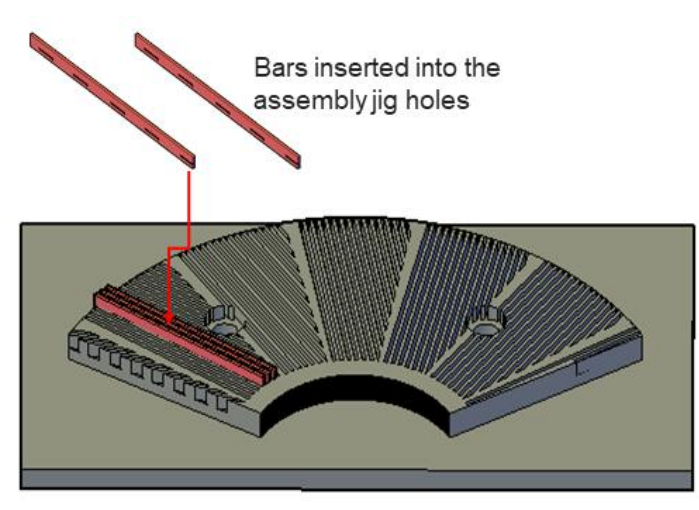

Step 1. Insertion of bars in the assembly jig.
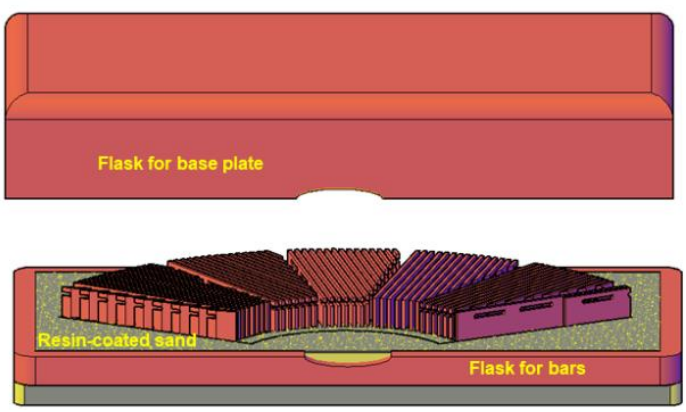

Step 3. Combining the upper mold where the bars are fitted and the lower mold flask corresponding to the plate base.

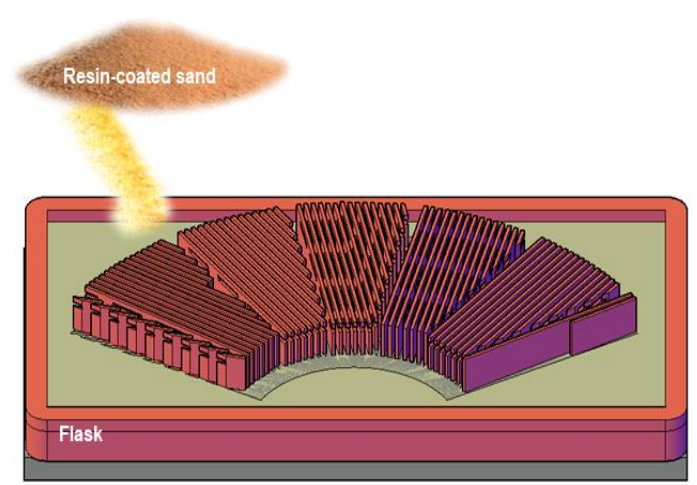

Step 2. After inserting all the bars into the assembly jig the flask was placed and resincoated sand was used to harden it at 200 to $500^{\circ} \mathrm{C}$.

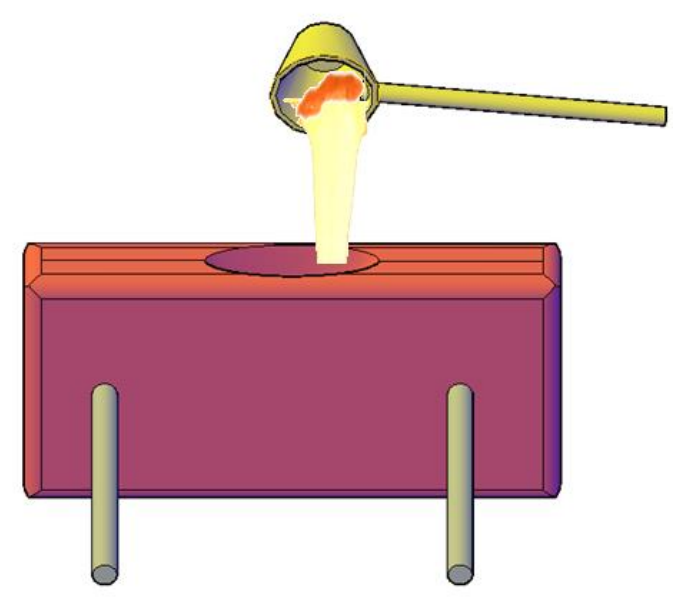

Step 4. Pouring a molten aluminum alloy into the clamped sand mold.

Fig. 3. Manufacturing process of a light bar plate 
The top surface of the bar was inserted into the assembly jig so that the bottom surface of the bar faced upward. The flask was placed on the bar-inserted assembly jig and packed with a resin-coated sand (refer to Step 2 in Fig. 3). The resin-coated sand was cured by heating it to a temperature of 200 to $500{ }^{\circ} \mathrm{C}$ using a liquefied petroleum gas torch (Samwoo, Goyang, Korea). When the flask holding the cured sand was lifted from the assembly jig, the bottom side of the bar to enter the base of the plate was exposed upward (see Step 3 in Fig. 3). After the flask holding the bars was combined with the other flask corresponding to the plate base, the resin-coated sand contained in the flask was again completely cured using the LPG heat source. When the molten aluminum alloy was carefully poured into the inlet of the clamped flask, the molten metal solution filled the empty spaces between the bars as well as the plate base (see Step 4 in Fig. 3). The molten aluminum alloy poured into the flask entered through the holes in each bar and served to fix them securely so that the bars did not come out of the plate base during refining. After the aluminum alloy was completely cooled, the flask containing the sand was removed to obtain a refiner plate segment. A post-treatment process was performed to control the uniform bar height and remove irregularities in the grooves (Fig. 4). The 3D models and the real image of the lightweight refiner plate without a draft angle are shown in Fig. 5.

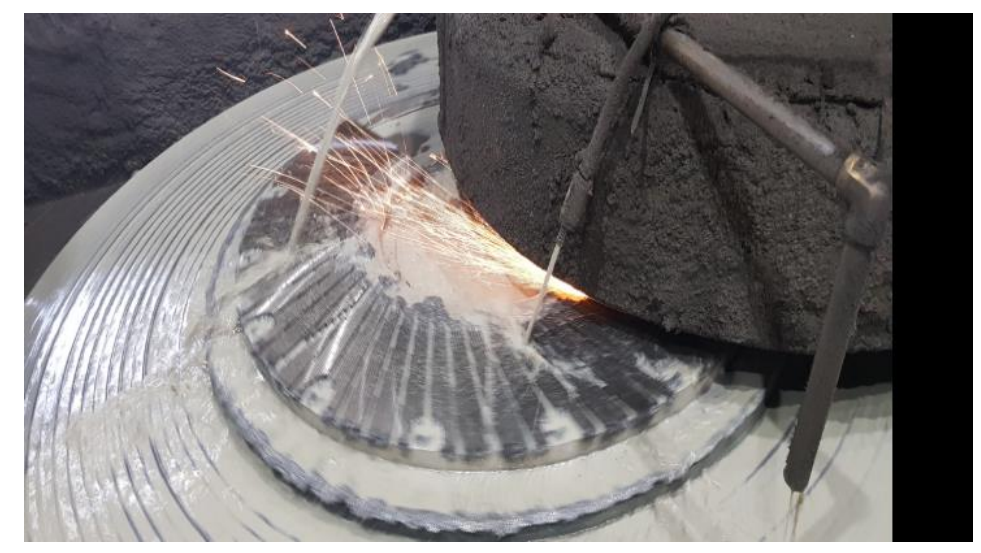

Fig. 4. Post-treatment process on the plate segments

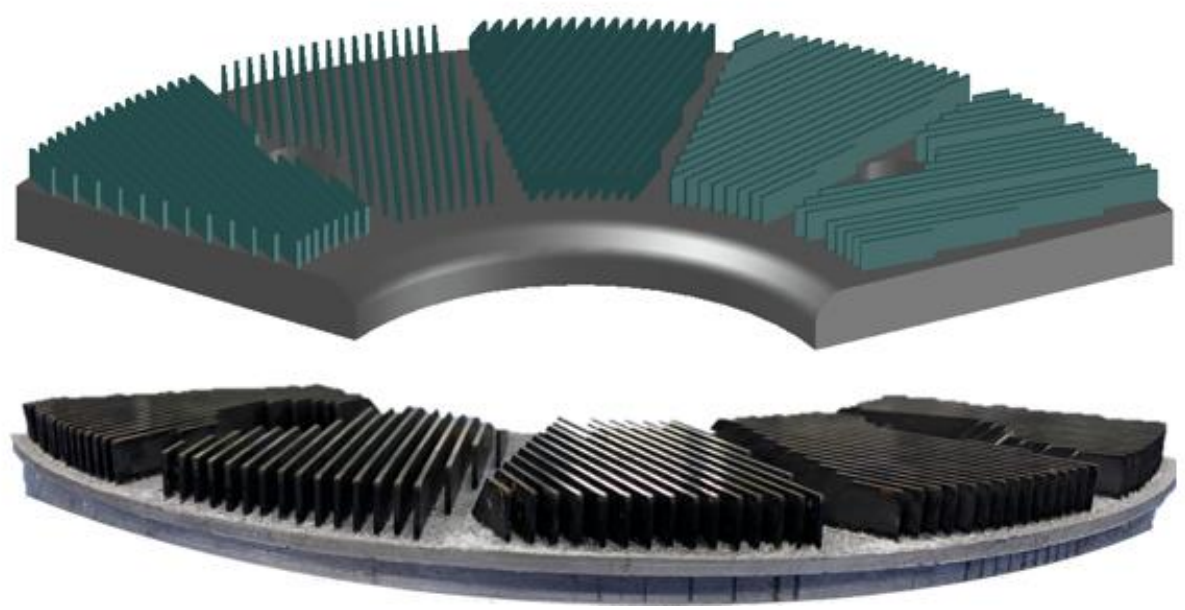

Fig. 5. 3D model and real image of the lightweight vertical fine bar plate 


\section{Refining Process}

The soaked pulp specimens of HwBKP were disintegrated using a Valley beater (Daeil Machinery Co., Daejeon, Korea) without a load at a consistency of $1.57 \pm 0.04 \%$ for at least 3 to $5 \mathrm{~min}$. When the pulp was properly disintegrated, extra water in the pulp stock was removed to adjust its consistency to around 4 to $5 \%$ for refining.

Refining was conducted using the laboratory single disk refiner (KOS1 Co., Gimhae, Korea) with two different plates, namely a general casting plate and the newly developed lightweight fine bar plate, shown in Fig. 6. The pulp stock was consecutively refined to achieve a Canadian freeness of approximately $200 \mathrm{~mL}$ which was measured based on ISO 5267-2 (2001) standard.

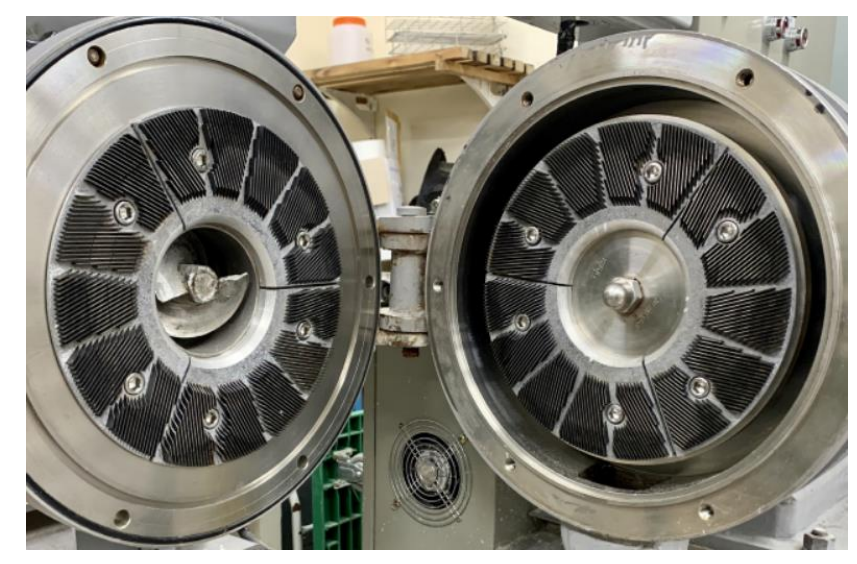

Fig. 6. Laboratory single disk refiner fitted with a lightweight fine bar plate

\section{Measurement of Pulp and Paper Properties}

Mean fiber length and fines contents $(\leq 0.2 \mathrm{~mm})$ were determined using FQA-360 (Optest Equipment Inc., Hawkesbury, Canada). Handsheets for measuring the physical properties of paper were made, conditioned, and tested according to the ISO 5269-1 (2005) standard. The physical properties, including tensile, tear and burst strength, were measured based on ISO 5270 (2012), ISO 1924-1 (1992), and ISO 1974 (2012) standards. Paper bulk was calculated using the basis weight of each sheet and thickness was measured using the L\&W caliper test (Micrometer, Kista, Sweden). Water retention value (WRV, g/g) was measured based on the ISO 23714 (2014) standard.

\section{RESULTS AND DISCUSSION}

\section{Comparison of Two Different Plates}

Refining is a process of mechanically improving the inner and outer structures of pulp fibers to enable them to achieve the final properties of paper or cardboard. Refining is often considered the most important stage in the papermaking process. To evaluate the effects of refining on pulp fibers, specific edge load (SEL), and specific surface load (SSL) should be calculated. ISO/TR 11371 (2013) provides guidelines for laboratory-level refining. Both SEL and SSL were also calculated based on ISO/TR guidelines as follows,

$$
\mathrm{SEL}=\frac{P_{\mathrm{t}}-P_{0}}{Z_{\mathrm{r}} \times Z_{\mathrm{st}} \times 1 \times n}=\frac{P_{\mathrm{t}}-P_{0}}{\operatorname{CLF} \times n}=\frac{P_{\mathrm{t}}-P_{0}}{\operatorname{CEL}}
$$


where SEL is the specific edge length $(\mathrm{J} / \mathrm{m}, \mathrm{W} \cdot \mathrm{s} / \mathrm{m}), P_{\text {tot }}$ is the total load power $(\mathrm{kW}), P_{0}$ is no-load power $(\mathrm{kW}), n$ is the rotation speed $(\mathrm{rev} / \mathrm{s}), Z_{\mathrm{r}}$ and $Z_{\mathrm{st}}$ are the number of rotor and stator bars, 1 is the bar length $(\mathrm{km})$, CLF is cutting length factor $(\mathrm{km} / \mathrm{rev})$, and CEL is cutting edge length $(\mathrm{km} / \mathrm{s})$. Two key parameters are given by Eqs. 2 and 3, as follows,

$$
\begin{aligned}
& \mathrm{SSL}=\frac{\mathrm{SEL}}{\mathrm{IL}} \\
& \mathrm{IL}=\frac{W_{\mathrm{r}}+W_{\mathrm{St}}}{2} \times \frac{1}{\cos \left(\frac{\alpha}{2}\right)}
\end{aligned}
$$

where SSL is the specific surface load $\left(\mathrm{J} / \mathrm{m}^{2}\right)$, IL is the bar width factor $(\mathrm{m}), W_{\mathrm{r}}$ is the rotor bar width $(\mathrm{m}), W_{\text {st }}$ is the stator bar width $(\mathrm{m})$, and $\alpha$ is the average intersecting angle $\left(^{\circ}\right)$.

As can be seen in Eq. 1, SEL does not consider stock concentration, bar and groove dimensions, and clearance between bars. In contrast, SSL in Eqs. 2 and 3 is calculated by considering the bar dimension and the intersecting angle of the bars, along with the intensity at the bar edges.

Table 2 compares structural differences between the casting plate, lightweight fine bar plate, SEL, and SSL accordingly. The casting plate had a draft angle of $4^{\circ}$, but the lightweight fine bar plate had a draft angle of $0^{\circ}$. The number of bars per segment was 165 for the casting plate and 270 for the lightweight fine bar segment. As the number of bars increased, the CEL became larger, allowing low intensity refining. The CEL of the casting plate was $37 \mathrm{~km} / \mathrm{s}$, and the CEL of the lightweight fine bar plate was double this, at 75 $\mathrm{km} / \mathrm{s}$.

Therefore, the SEL of the lightweight fine bar plate became lower, which allowed lower intensity refining than the casting plate. The SSL was greatly affected by SEL and bar width. That is, assuming that there are two plates with the same SEL, it is possible to prevent excessive fiber cutting by reducing the energy transmitted onto the fibers using a plate with a wider bar.

Another advantage of the lightweight fine bar plate compared to the casting plate was weight reduction. The weight per segment was approximately $47 \%$ lighter compared to the casting plate segment. This can reduce the power required during the initial operation of the refiner and facilitate plate replacement.

\section{Hardness Change by Heat Treatment}

The heat treatment of ferrous metals usually consists of annealing, normalizing, hardening, and/or tempering. However, for a plate manufactured using an insertion method of dissimilar metals, the casting process adversely affects the hardness of the metals corresponding to the bars inserted into the base plate (refer to Table 3 ). If the metal material used in the bar is not heat-treated, as shown in Table 3, the spots $(2,4)$ inserted into the base are softened in the casting process and the bar hardness is reduced. If the hardness of the bar falls, it can easily bend due to the impact between the rotor and stator during refining, shortening the life of the refiner plate.

In contrast, if the bar is heat-treated before insertion into the plate base, there is no material softening during the casting process, as shown in Table 4 . Therefore, insertion of the bars into the plate base must be preceded by heat treatment to prevent deformation of the bars during use. 
Table 2. Comparison of Refiner Plate Segments With and Without a Draft Angle for HwBKP

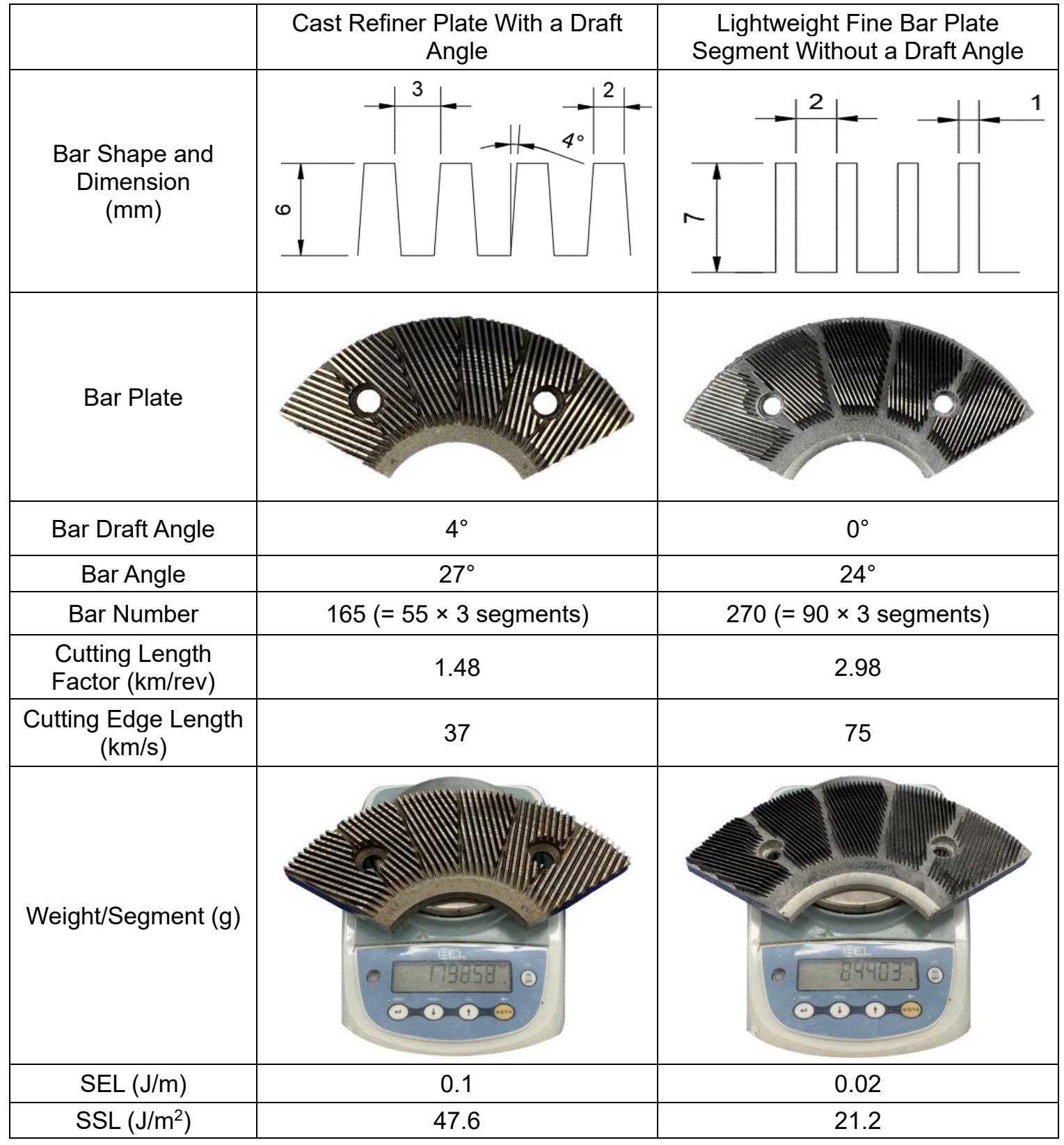

Table 3. Rockwell Hardness Test Without Heat Treatment

\begin{tabular}{|c|c|c|c|c|c|}
\hline Bar After Casting & & 2 & 3 & 4 & \\
\hline Indenter Position & 1 & $2^{*}$ & 3 & $4^{*}$ & 5 \\
\hline $\begin{array}{c}\text { Rockwell Hardness } \\
\left(H_{\mathrm{RC}}\right)\end{array}$ & 50.9 & 30.8 & 51.1 & 29.9 & 50.7 \\
\hline
\end{tabular}


Table 4. Rockwell Hardness Test After Heat Treatment

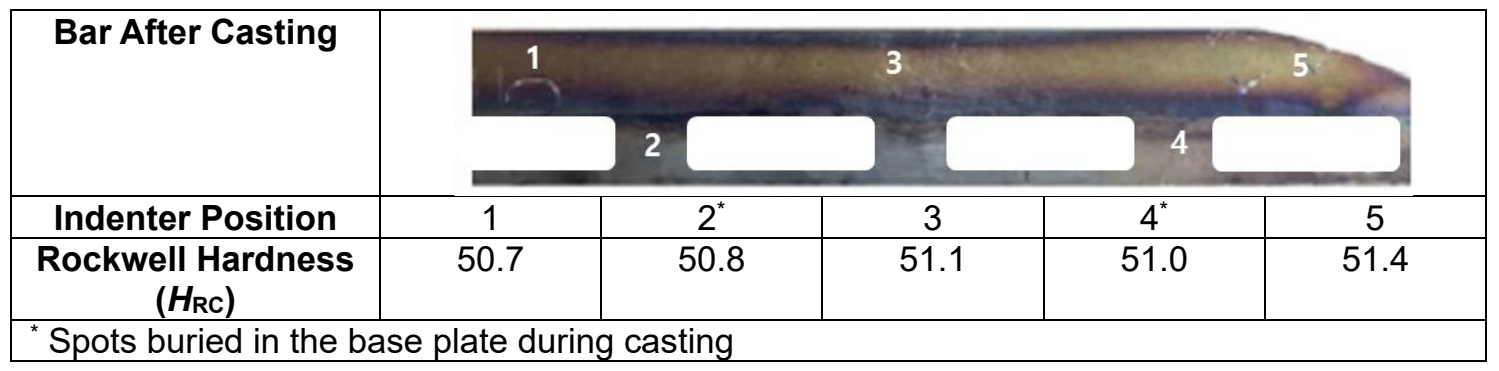

\section{Throughput Comparison Between Two Different Plates}

When using a fine bar plate with a narrow groove width, there is always a concern about a decrease in stock throughput. Considering the amount of pulp stock passing through one single groove, the throughput of pulp stock that can be handled in a fine bar plate will certainly be less than that of the conventional casting plate. Assuming that the groove length is $10 \mathrm{~cm}$, the volume of one single groove through which the pulp stock passes is $1.5 \mathrm{~cm}^{3}$ for the casting plate and $1.4 \mathrm{~cm}^{3}$ for the lightweight fine bar plate. The groove volume of the casting plate is larger. However, as shown in Fig. 7, when comparing the total groove volume within a certain plate length, the volume of the casting plate was $3 \mathrm{~cm}^{3} / \mathrm{cm}$, and the volume of the lightweight fine bar plate was $4.8 \mathrm{~cm}^{3} / \mathrm{cm}$. That is, if only one single groove volume was compared, the casting plate had a larger groove volume than the lightweight fine bar plate, but when compared with the entire plate, the number of grooves in the lightweight fine bar plate increased, so the total volume through which the pulp stock passed was forced to increase approximately $27 \%$ compared to the casting plate.

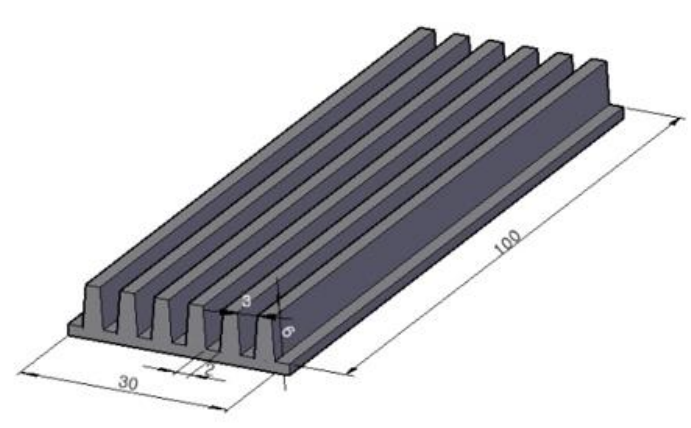

(A) Casting plate

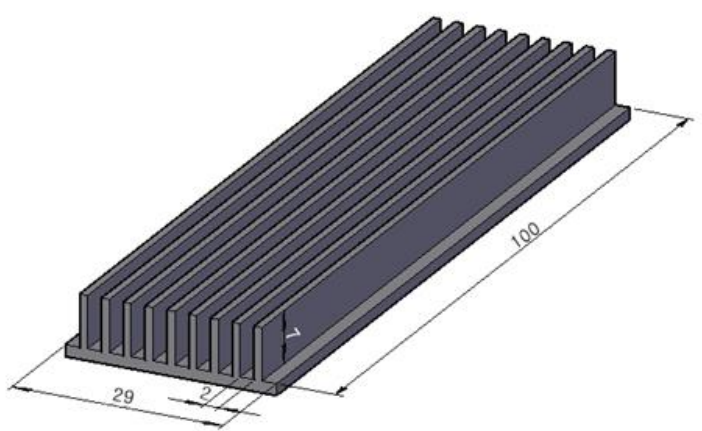

(B) Lightweight fine bar plate

Fig. 7. Comparison of feeding volumes of the pulp stock into the grooves

Figure 8 is a graph comparing the stock throughput of the casting plate and the lightweight fine bar plate during refining. As refining progressed, the stock throughput of the lightweight fine bar plate more than doubled compared to the casting plate. As a result, it could be seen that the lightweight fine bar plate was a more effective bar plate from the viewpoint of productivity. This result - that the fine bar plate had a higher throughput than the normal casting plate - was consistent with the findings of previous studies (Müller 2016; AFT Catalog 2017). 


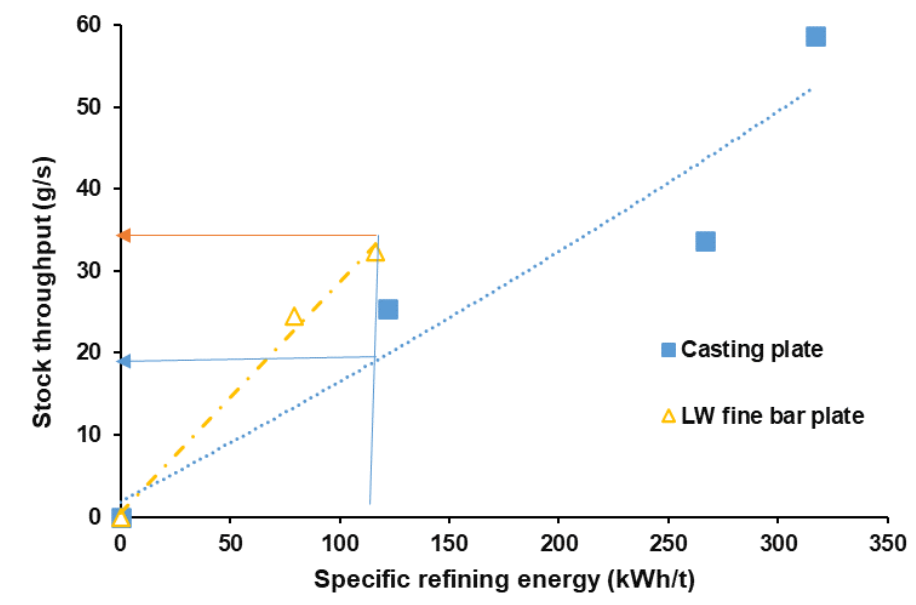

Fig. 8. Throughput comparison of the pulp stocks from the general casting plate and the lightweight fine bar plate
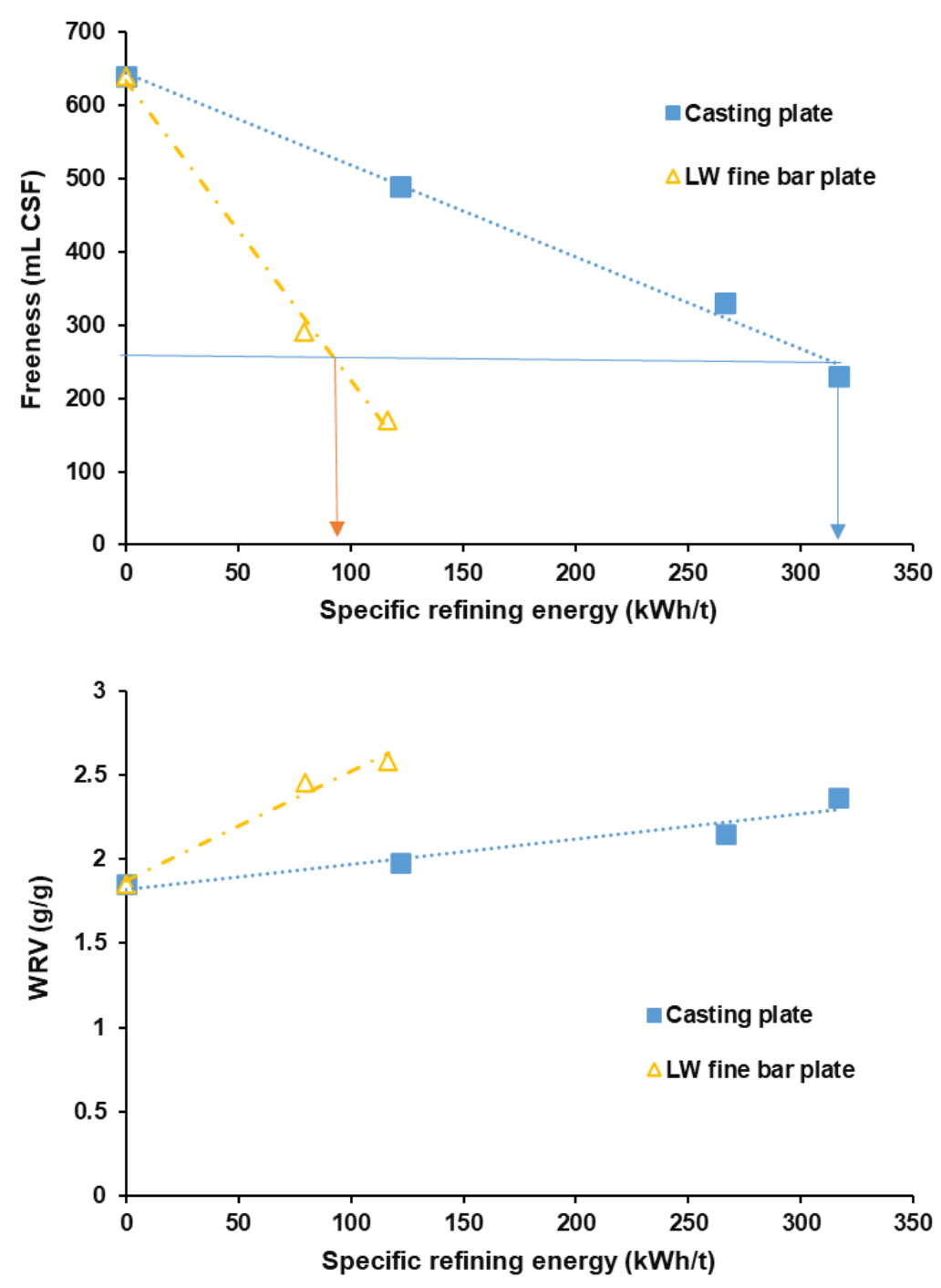

(a) Freeness

(b) Water retention value

Fig. 9. Freeness $(A)$ and water retention value $(B)$ of pulp fibers refined by bar plates with and without a draft angle, respectively 


\section{Comparison of Fiber Properties}

Drainage rate during papermaking is closely related to fiber wall delamination and external fibrillation of individual pulp fibers and generation of short fibers during refining. Because such refining effects can be indirectly confirmed through pulp freeness, the end point of refining is determined by measuring freeness. In Fig. 9(a), the refining energy required to reach the same freeness level - around $200 \mathrm{~mL} \mathrm{CSF}$ - by two plates with different fillings was compared. Unlike the casting plate, the lightweight fine bar plate dropped the pulp freeness quickly, and the refining energy consumed by the lightweight fine bar plate to reach the same freeness was approximately 3 times less than that of the casting plate. It was estimated that the lightweight fine bar plate had a sharper bar edge and a larger number of bars, thus achieving more rapid structural modification of the fibers.
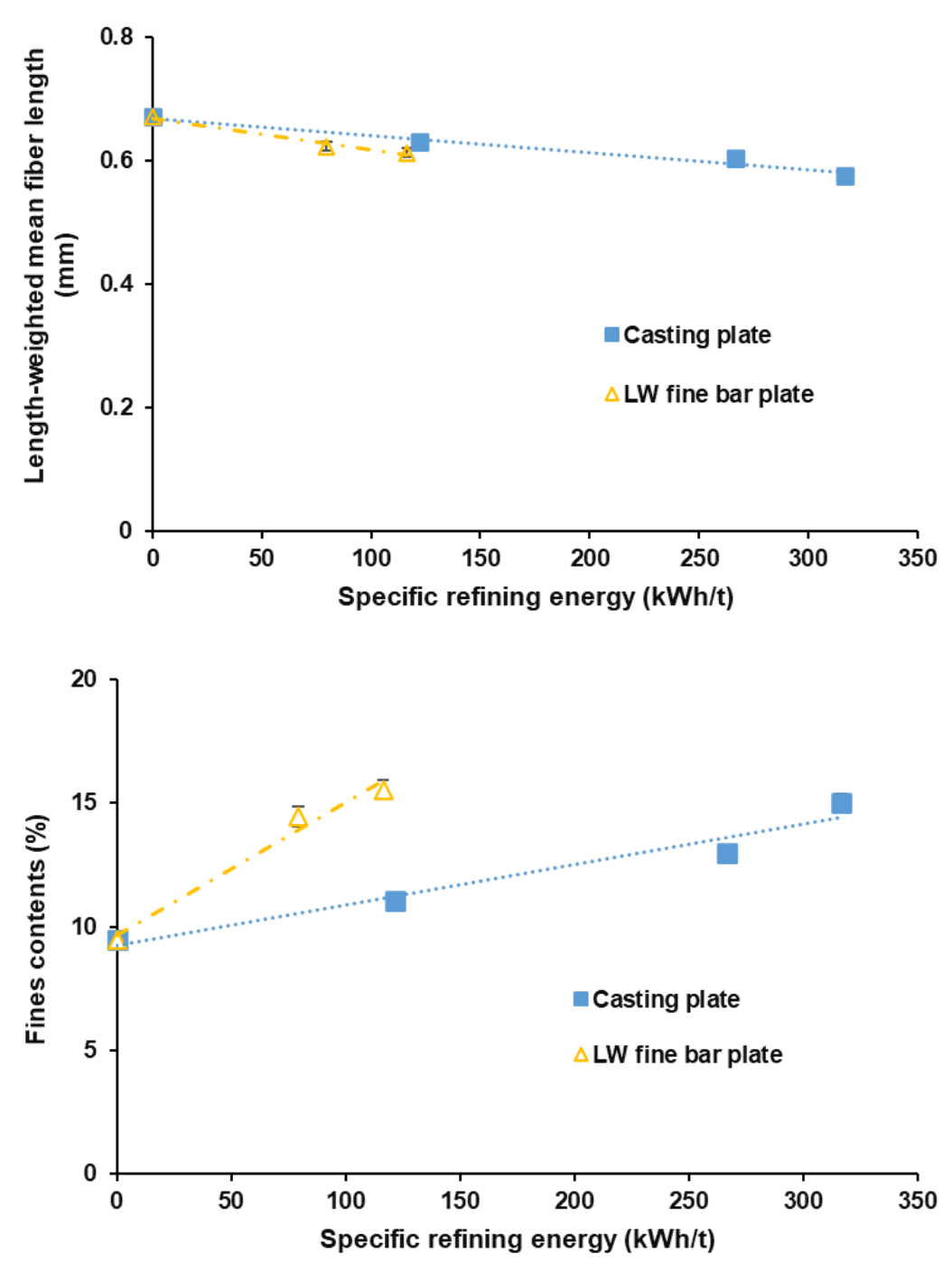

(a) Mean fiber length

(b) Fines contents

Fig. 10. Mean fiber length and fines contents of pulp fibers refined by bar plates with and without a draft angle, respectively

As shown in Fig. 9(b), as refining progressed, it was found that the lightweight fine bar plate had a larger WRV of the pulp fibers compared to the casting plate. The WRV is a 
measure of the capacity of pulp fibers to hold water. It is well known that WRV is closely related to internal and external fibrillation and fines fraction. That is, it was considered that the lightweight fine bar plate induced more fibrillation of the inner and outer walls of the pulp fibers during refining, and at the same time generated more fines, thereby affecting the faster increase of WRV of the pulp fibers.

In Fig. 10, as the refining progressed, the mean fiber length became slightly shorter, with more fines being generated by the lightweight fine bar plate compared to the casting plate. It was estimated that the production of more fines contents by the lightweight fine bar plate was due to the occurrence of more secondary fines through fibril detachment from the continuous impacts on the fibers' outer walls. It was thought that this contributed to a greater increase in WRV by the lightweight fine bar plate. Mayr et al. (2017) also showed that WRV increased linearly when fines contents increased.

In conclusion, it was ascertained that the lightweight fine bar plate could remarkably reduce refining energy and induce more fibrillation of fiber walls while minimizing fiber length loss during refining.

\section{Change of Paper Properties}

Figure 11 shows the effects of the refiner plate with different fillings on the physical properties of paper. Paper requires enough refining to promote the generation of internal bonds, increase strength properties, and improve smoothness. However, too much refining negatively affects its bulk and stiffness. Refining using the lightweight fine bar plate resulted in more bulk reduction compared to the casting plate. Unlike the paper bulk, the strength properties of the paper showed different behavior depending on the plates with different fillings. Tensile strength and burst strength of the paper rose more steeply with the lightweight fine bar plate. The tear strength of the paper, which was greatly affected by the fiber length, also increased slowly with the casting plate, but increased quickly with the lightweight fine bar plate. In other words, low intensity refining was available in the lightweight fine bar plate, thereby inducing internal and external fibrillation while minimizing reduction in fiber length.

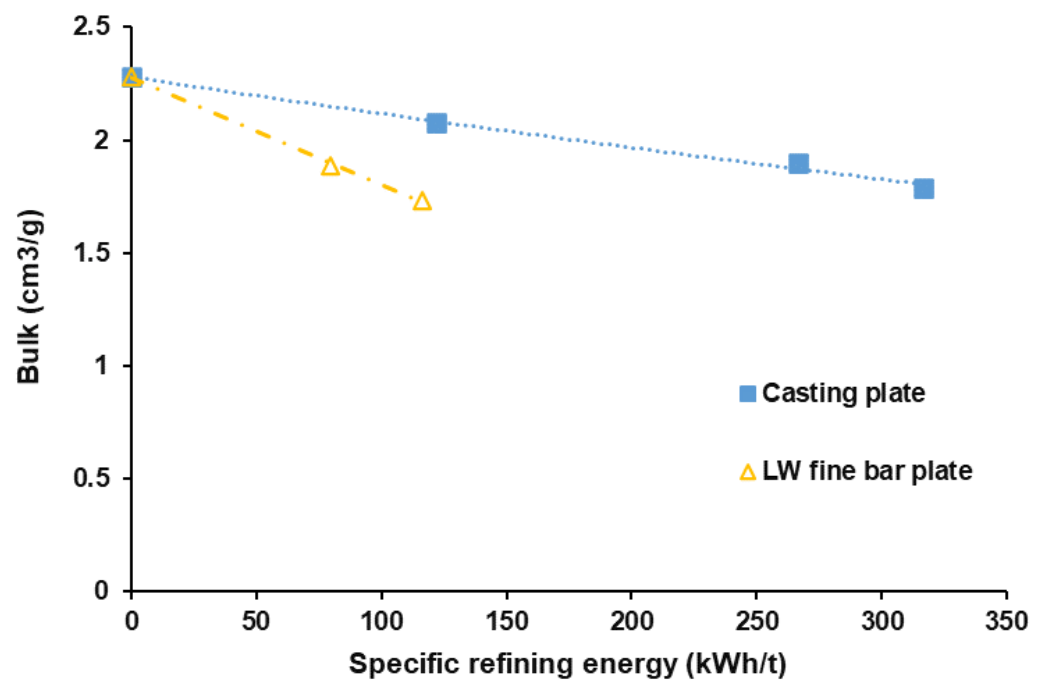

(a) 


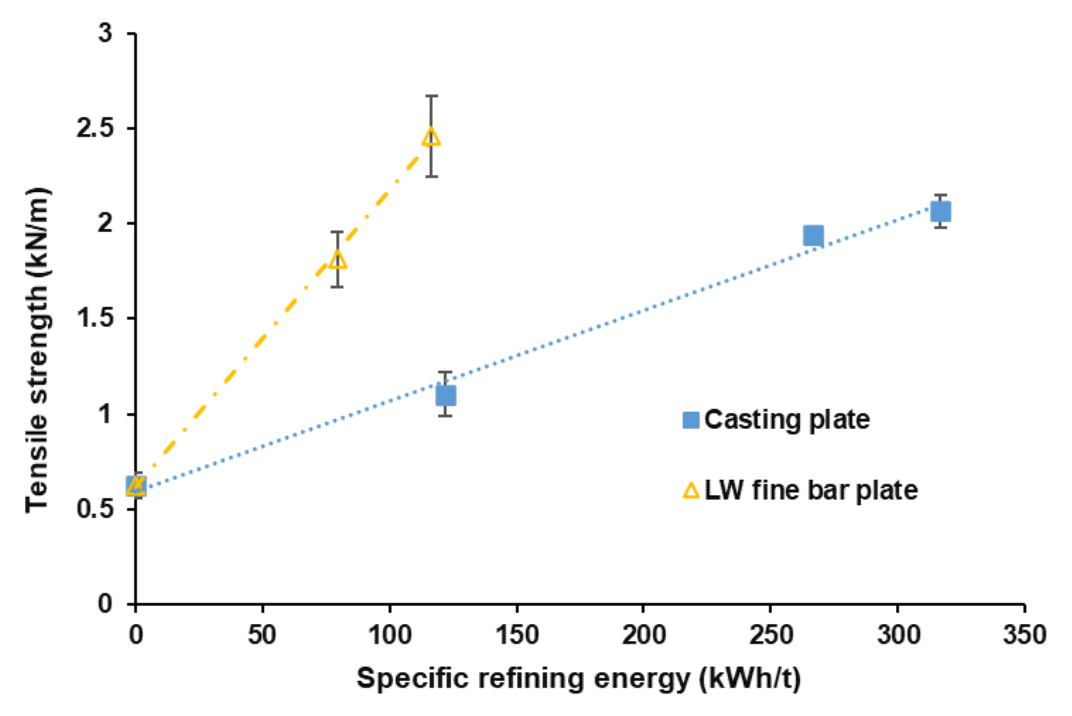

(b)

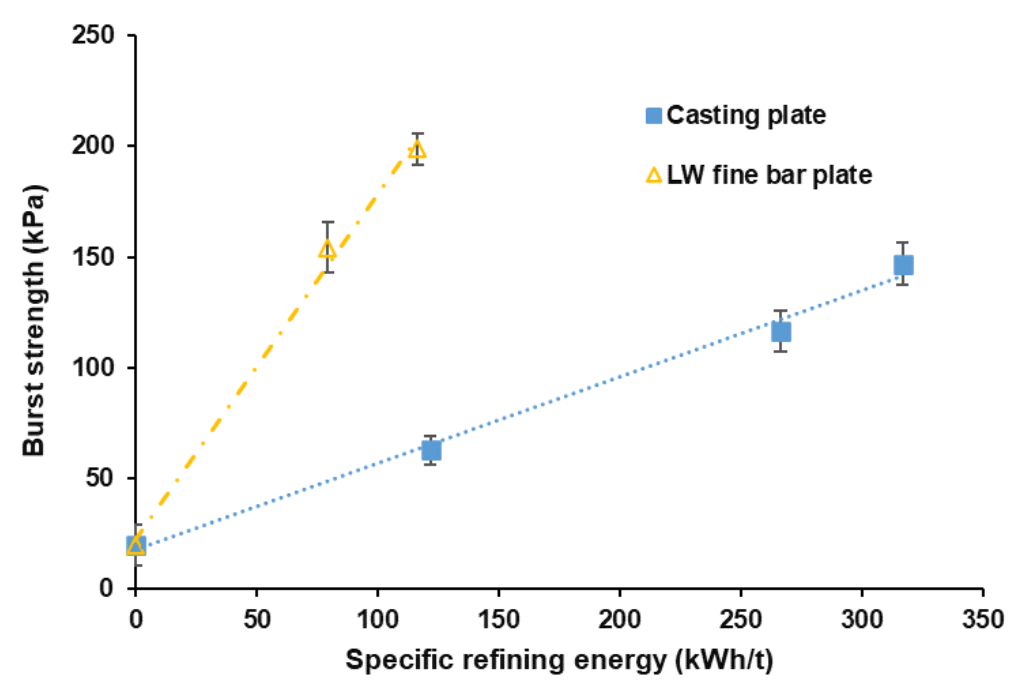

(c)

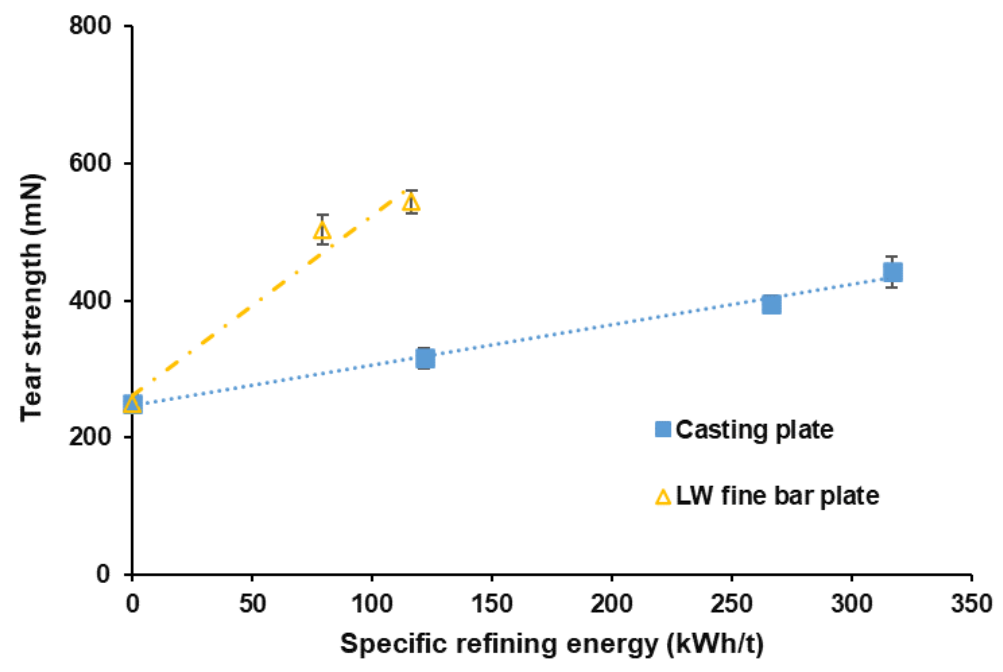

(d)

Fig. 11. Change of physical properties of papers refined by bar plates with and without a draft angle, respectively; a) bulk, b) tensile strength, c) burst strength, and d) tear strength 
It was considered that this contributed to improving fiber conformability and had a positive effect on the improvement of the strength properties of paper. Finally, it could be concluded that the new lightweight fine bar plate contributed to a faster increase in tear strength because it had a sharper bar edge and more bars were inserted to enable much lower intensity refining, relative to the default plate.

\section{CONCLUSIONS}

1. The refiner plate manufactured by sand casting should have a draft angle of the bars formed on the plate base to prevent breakage of the sand during the casting process. Therefore, it is difficult to manufacture a fine bar plate capable of low intensity refining using the sand-casting method. In addition, the casting plate has poor workability because one segment is heavy due to the nature of the metal components. In this study, the authors developed a new manufacturing technology that was different from the method currently in use for manufacturing fine bar plates and compared the effects with the existing casting plates.

2. The plate base was a lightweight aluminum alloy and the bars were a stainless-steel alloy with excellent wear resistance. Bars were inserted into the plate base mold, and then the molten aluminum alloy was poured into the mold to fix the bars to the base. Because the bars inserted into the plate were vertical, without a draft angle, the stock throughput was improved by approximately $27 \%$ compared to the casting plate during refining.

3. Because the lightweight fine bar plate has sharp bar edges, it was possible to remarkably reduce the energy required to reach the target freeness. In addition, unlike the casting plate, the lightweight fine bar plate was able to greatly improve the strength properties of the paper while minimizing the reduction of fiber length.

\section{ACKNOWLEDGNEMENTS}

This research was supported by the Basic Science Research Program through the National Research Foundation of Korea (NRF) funded by the Ministry of Education (Grant no: 2017R1D1A3B04027967). The authors also thank the KOS1 officials for helping to manufacture the refiner plate.

\section{REFERENCES CITED}

Aikawa Fiber Technology (AFT) Catalog (2017). Finebar Refiner Plates: Low-intensity Refining at its Finest, AFT, Quebec, Canada.

Baker, C. F. (1995). "Good practices for refining the types of fiber found in modern paper furnishes," TAPPI J. 78(2), 147-153.

ISO 1924-1 (1992). "Paper and board - Determination of tensile properties - Part 1:

Constant rate of loading method," International Organization for standardization, Geneva, Switzerland.

ISO 1974 (2012). "Paper -- Determination of tearing resistance - Elmendorf method," 
International Organization for Standardization, Geneva, Switzerland.

ISO 5267-2 (2001). "Pulps — Determination of drainability — Part 2: "Canadian

Standard" freeness method," International Organization for Standardization, Geneva, Switzerland.

ISO 5269-1 (2005). "Pulps - Preparation of laboratory sheets for physical testing — Part

1: Conventional sheet-former method," International Organization for

Standardization, Geneva, Switzerland.

ISO 5270 (2012). "Pulps - Laboratory sheet - Determination of physical properties," International Organization for Standardization, Geneva, Switzerland.

ISO 23714 (2014). "Pulps - Determination of water retention value (WRV)," International Organization for Standardization, Geneva, Switzerland.

ISO/TR 11371 (2013). "Pulps - Basic guidelines for laboratory refining," International Organization for Standardization, Geneva, Switzerland.

J\&L Fiber Services (2006). J\&L Refiner Plates: Ultra-Bar ${ }^{T M}$ Patterns with PowerCast ${ }^{T M}$ Technology, Valmet Inc, Waukesha, WI, USA.

Kay, I. M. (2002). "Patternmaking 'tricks' for better castings," Engineered Casting Solutions 4(1), 48-49.

Kerekes, R. J. (1990). “Characterization of pulp refiners by a C-factor," Nordic Pulp Pap. Res. J. 1, 3-8. DOI: 10.3183/npprj-1990-05-01-p003-008

Lee, M.-S., Kim, C.-H., Lee, J.-Y., Park, S.-H., and Min, B.-G. (2019). "Performance evaluation of bar plates without a draft angle to improve refining efficiency," J. Korea TAPPI 51(5), 5-11. DOI: 10.7584/JKTAPPI.2019.10.51.5.84

Lumiainen, J. (2000). "Refining of chemical pulp. Chap. 4 Papermaking Part 1: Stock preparation and wet end," in: Papermaking Science and Technology Series Volume 8, Paulapuro, H. (ed.), Paperi ja Puu Oy, Peachtree Corners, GA, USA, pp. 86-122.

Mayr, M., Eckhart, R., Winter, H., and Bauer, W. (2017). "A novel approach to determining the contribution of the fiber and fines fraction to the water retention value (WRV) of chemical and mechanical pulps," Cellulose 24(7), 3029-3036.

Müller, M. (2016). Energy-efficient Fiber Treatment with Durabond Refiner Plates, Andrtiz Tech Talk 34(2), Wien, Austria.

Nissan, A. H. (1977). Lectures on Fiber Science in Paper, Pulp and Paper Technology, Series Vol. 4, Joint Textbook Committee of the Paper Industry, New York, NY, USA.

Ratnieks, E., Massoquete, A., Demuner, B. J., Robinson, D., and DeFore, R. (2007). "Ultra low intensity refining of eucalyptus pulp for papermaking," in: International Pulp Refining Seminar, Otaniemi, Espoo, Finland, pp. 7-13.

Robinson, D., DeFoe, R., and Gooding, R. (2010). "Novel technology for ultra-low intensity refining," in: World Pulp \& Paper 2010, REM Productions, Milan, Italy, pp. 20-23.

Article submitted: August 20, 2020; Peer review completed: October 10, 2020; Revised version received and accepted: October 12, 2020; Published: October 16, 2020.

DOI: 10.15376/biores.15.4.9128-9142 